\title{
RE-OS ISOTOPE SYSTEMATICS OF PERIDOTITIC DIAMOND INCLUSION SULFIDES FROM THE PANDA KIMBERLITE, SLAVE CRATON
}

\author{
Kalle Westerlund ${ }^{1}$, Steven B. Shirey ${ }^{2}$, Stephen H. Richardson ${ }^{1}$, John J. Gurney ${ }^{1}$, Jeffrey W. \\ Harris $^{3}$ \\ ${ }^{1}$ Department of Geological Sciences, University of Cape Town, South Africa $;{ }^{2}$ Department of Terrestrial Magnetism, \\ Carnegie Institution of Washington, Washington, DC, U.S.A.; ${ }^{3}$ Division of Earth Sciences, University of Glasgow, Scotland
}

\section{INTRODUCTION}

It has long been known that parts of the sub-cratonic lithosphere are as ancient as the Archaean crust (Richardson et al., 1984). However, the genetic relationship between the Archaean lithosphere and its overlying crust remains enigmatic in part because there is a lack of lithospheric samples suitable for precise isotope dating. Melt-depleted peridotites in cratonic keels generally give neo- to meso-Archaean model ages and Re depletion ages (e.g. Carlson et al., 1999), while isochron dating can be hampered due to the opensystem character of these rocks. In concequence, well constrained initial ${ }^{187} \mathrm{Os} /{ }^{88} \mathrm{Os}$ compositions for the melt-depleted Archaean lithosphere are also absent and initial Os isotope compositions for the ancient mantle have until now been obtained from mantle melts (Puchtel et al., 2001 and references therein).

Minerals included in diamond are protected from the surrounding environment by their robust and chemically inert host. Previously, sulfide inclusions from the eclogitic paragenesis have been successfully analysed and shown to preserve ancient Re-Os isotope systematics (e.g. Pearson et al., 1998; Richardson et al., 2001; Shirey et al., 2001; Shirey et al. 2002). Here we present $\mathrm{Re}-\mathrm{Os}$ isotope data for peridotitic sulfide inclusions in diamonds from the Panda kimberlite, Slave craton. This is the first large peridotitic sulfide inclusion suite to be analyzed by single-inclusion, bulkanalysis Re-Os technique.

Eight of the eighteen diamonds hosting the sulfides were cut into plates parallel to the 110 crystal plane to facilitate cathodoluminescence imaging, FTIR absorption analysis and carbon and nitrogen isotope microanalysis prior to extraction of the sulfides (Westerlund et al, this volume). Re and Os may partition differently into the separate sulfide phases during late stage exsolution from a monosulfide solid solution (Richardson et al., 2001). Therefore, all the sulfides were carefully extracted by gently cracking the diamonds to ensure complete recovery of each grain, although this was sometimes difficult because of the micromanipulations involved. Eight of the diamonds contained multiple sulfide inclusions, 26 sulfides were recovered in all. The analytical method is described in (Pearson et al., 1998; Richardson et al., 2001).

\section{RE AND OS CONCENTRATIONS}

The sulfides show a very large range in Os concentration from $824 \mathrm{ppb}$ to 3.8 atomic \% (Figure 1) with the bulk of the sulfides having substantially higher Os concentrations than previously analyzed peridotitic diamond sulfide inclusions ( 650-20000 ppb; Pearson et al., 1998, 1999a, 1999b). The sulfides also show a large range in Re concentration from $74 \mathrm{ppb}$ to 2659 ppb. However, the high Os contents are not mirrored by exceptionally high Re contents, which results in Re/Os ratios that are up to 100 times lower than those of cratonic peridotites. Sulfide PA87c differs from the rest of the sulfides with its combined low Re and Os concentrations (74 ppb and 4296 ppb respectively; Figure 1).

Some sulfides display rather high $\mathrm{Re} / \mathrm{Os}$ ratios mainly because of fairly high Re concentrations. While the Os and Ni concentrations of these sulfides are indicative of a peridotitic origin, the highest Re/Os ratios are similar to those of komatiite and even basalt/eclogite. Apart from dominant pentlandite, semi-quantitative SEM analyses has identified $\mathrm{Cu}$-bearing sulfide phases and $\mathrm{Fe}-\mathrm{Ni}-\mathrm{Cu}$ alloy in several grains. The high $\mathrm{Re} / \mathrm{Os}$ ratios, therefore, may be dependent on the modal abundance of monosulfide solution (from which the $\mathrm{Cu}$ phases and pentlandite are derived; Craig and Kullerud, 1969) and metal alloys. Modal abundances may also explain the extremely high Os concentrations of some sulfides and the fact that Os concentrations in sulfides from individual diamonds differ with a factor of up to 45 . 


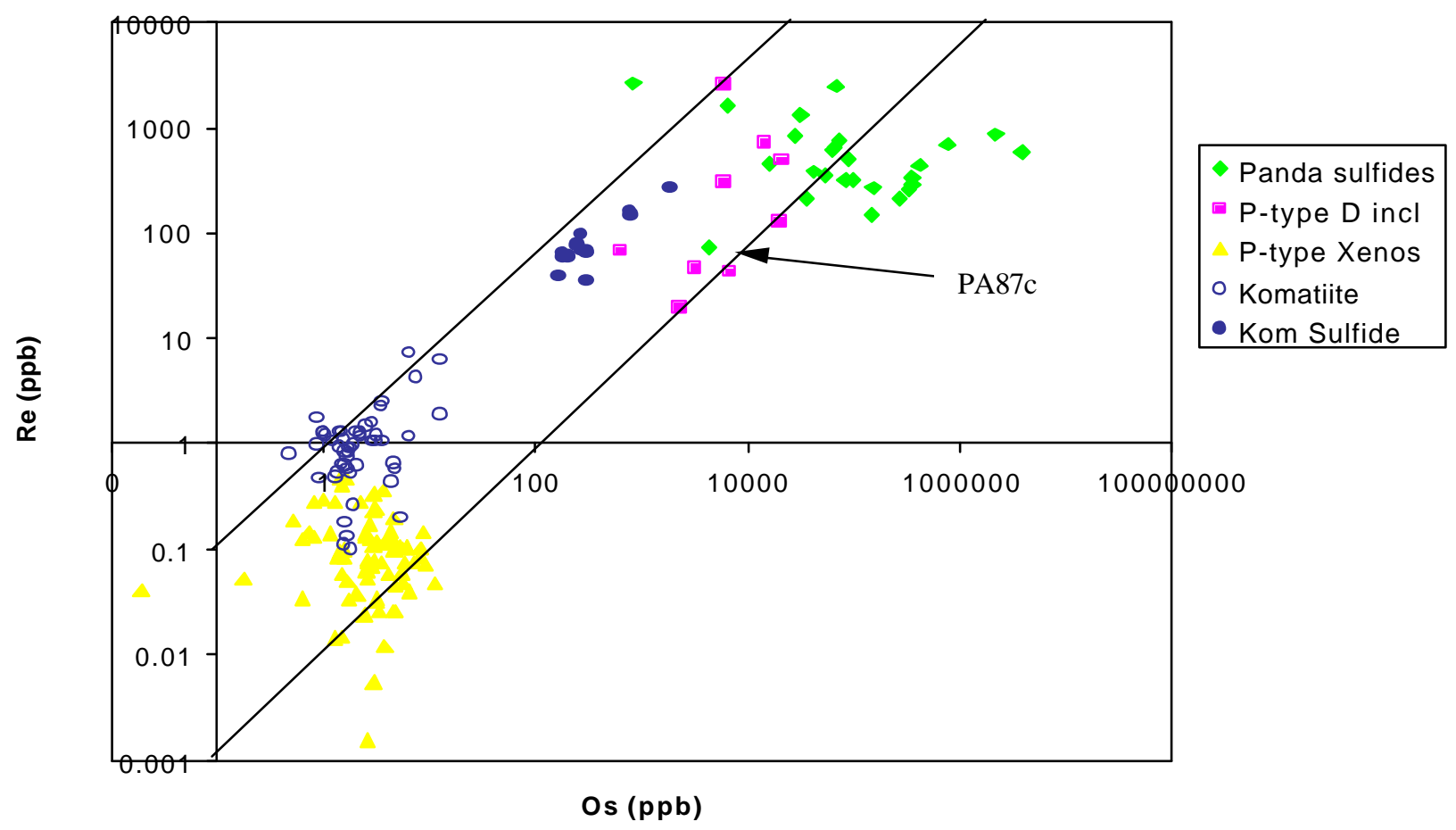

Figure 1: Re and Os concentrations for Panda sulfide inclusions compared to other peridotitic diamond sulfide inclusions, peridotitic mantle xenoliths, komatiites and komatiitic sulfides. Inserted are lines with constant Re/Os ratios of 1 and 0.01 .

\section{RE-OS ISOTOPE SYSTEMATICS}

Nineteen of the twenty-six analysed sulfides are well correlated in the Re-Os isochron diagram. These sulfides form the designated groups I and II in Figure 2. A regression of all nineteen sulfides yields an age of $3753 \pm 380 \mathrm{Ma}$ and an initial ${ }^{187} \mathrm{Os} /{ }^{188} \mathrm{Os}$ of 0.1091 (MSWD=3.6). However, all the eight inclusions recovered from diamonds PD5, PD6, PD7 and PD9 (group II sulfides) form a tight cluster, which deviates slightly from the strong correlation displayed by the group I sulfides towards lower less radiogenic compositions. This may have geological significance and could indicate either that the two groups are temporally distinct or that they are co-genetic, the group II sulfides forming with a slightly lower initial ${ }^{187} \mathrm{Os} /{ }^{188} \mathrm{Os}$. In the first case, the determined primitive mantle model ages of 2.68-2.72 Ga may have geological meaning. However, based on the similarities in FTIR absorption and nitrogen isotope characteristics, the latter scenario is preferred. Although one group I inclusion each from diamonds PD2 and PD10 partly over-lap with the group II data (Figure 2), they are assigned to group I since a second inclusion from each diamond plot further up the group I trend. A regression of the 11 group I sulfides gives an age of $3443 \pm 450 \mathrm{Ma}$ and an initial ${ }^{187} \mathrm{Os} /{ }^{188} \mathrm{Os}$ of 0.1093 (MSWD=2.9).
Sample PA93a (see Figure 2) has a very high in-run precision and plots significantly off the group I correlation line. If this sample is excluded, a 10-point age of $3408 \pm 280 \mathrm{Ma}$ with an initial ${ }^{187} \mathrm{Os} /{ }^{188} \mathrm{Os}$ of 0.1093 is obtained (MSWD=0.75) (Figure 3). Apart from it being an outlier, there is no a priori reason for the exclusion of sample PA93a (however, see below for possible reason for the deviation). Sample PD4 with the large errors in Figure 3 represents a combination of six sulfides from one diamond. The sulfides were touching or interconnected in a complex system of "black rosettes" and the individual sulfides scatter around the isochron. Since the recombination of all sulfides conforms to the isochron, this is indicative of late-stage inter-inclusion diffusion of Re and Os.

Five samples with high to very high ${ }^{187} \mathrm{Re} /{ }^{188} \mathrm{Os}$ ratios are off-scale in Figure 2 and deviate from the isochron in Figure 3 and will now be considered. Samples PA91a, PA92a and PA 97a have marginally to substantially suprachondritic present-day ${ }^{187} \mathrm{Os} /{ }^{188} \mathrm{Os}$ ratios. Further, their Os isotope compositions are not supported by Re so that their chondritic model ages are negative $(-0.69 \mathrm{Ga})$ or exceed the age of the Earth $(6.18$ and $6.20 \mathrm{Ga}$ ). This would demand formation from a basaltic precursor with a significantly suprachondritic $\mathrm{Re} / \mathrm{Os}$ ratio, which belies the high Os and $\mathrm{Ni}$ 


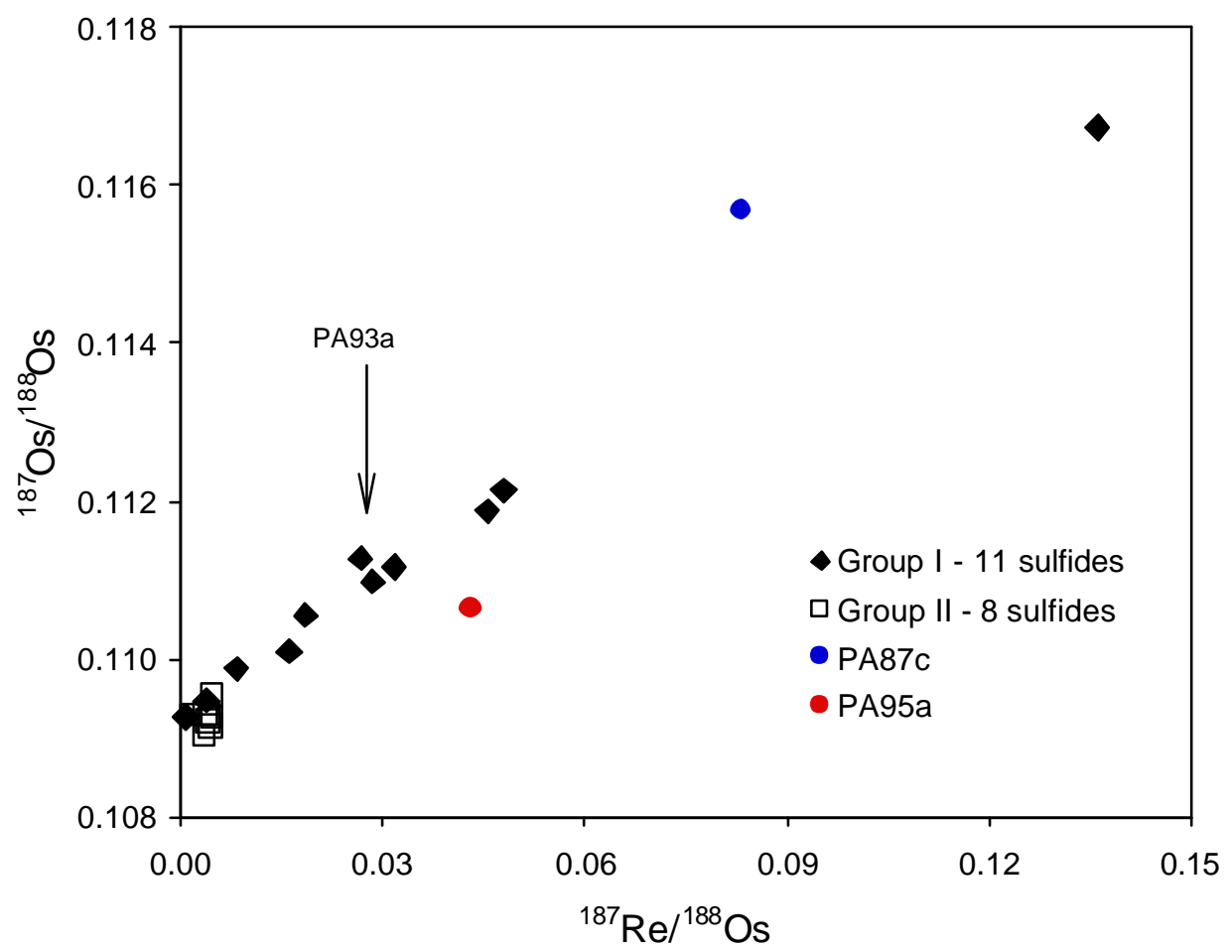

Figure 2: Re-Os isochron diagram showing the different groups and sulfides discussed in the text.

concentrations of the inclusions. Another two samples (PA89a and PA94a) have slightly subchondritic ${ }^{187} \mathrm{Os} /{ }^{188} \mathrm{Os}$ and chondritic model ages of 1.83 and 1.22 Ga respectively. Together, these five samples display a range in ${ }^{187} \mathrm{Re} /{ }^{188} \mathrm{Os}$ of 0.14-19.8 (compare to $\mathrm{x}$-axis in Figure 3) and with increasing ${ }^{187} \mathrm{Re} /{ }^{188} \mathrm{Os}$ they plot increasingly further away from the $3.4 \mathrm{Ga}$ isochron towards more radiogenic ${ }^{187} \mathrm{Os} /{ }^{188} \mathrm{Os}$ compositions. No meaningful isochron relationships can be obtained from these samples by themselves or in combination with any other sulfides. The possibility that the pattern observed could be the result of Re and/or Os isotope reequilibration through interaction with an external environment is discounted, because no cracks to the diamond surface were observed. Additionally, the appearance and the major element compositions of the sulfides do not indicate alteration. An alternative possibility is that a Re-bearing phase may have been partially lost during micro-manipulation of the samples. Diamond inclusion sulfides are generally surrounded by a "black rosette" - a thin film of sulfide occupying cracks induced by the diamond/inclusion differential expansion during transport to the Earth's surface. These films can be of significant thickness closest to the sulfide grain but cannot be recovered together with the sulfide grain. Thus, in some cases, a phase with higher $\mathrm{Re} / \mathrm{Os}$, which may have exsolved from a monosulfide solution could have been lost from the analysis and this explanation is plausible because these particular samples plot increasingly further away from the derived isochron with increasing Re content.

Sulfide PA87c plots significantly above the group I trend (Figure 2) and has a model age of $2.25 \mathrm{Ga}$. This sulfide was a highly symmetrical cubo-octahedral crystal with very smooth surfaces compared to the more irregular forms and pitted surfaces observed for the bulk of the sulfides. The distinctive morphology may be indicative of growth under different chemical/physical conditions and together with the low $\mathrm{Re}$ and Os concentrations mentioned earlier may be indicative of a separate population. Alternatively, the deviation of this sulfide (as well as PA93a discussed above) from the isochron the isochron could be due to loss of a high $\mathrm{Re} / \mathrm{Os}$ phase as discussed above.

One sulfide (PA95a) has similar $\mathrm{Re}$ and Os concentrations to the group I and group II sulfides but it deviates significantly below the derived isochron (Figure 1). Os isotope heterogeneity in the formation environment (see above) may be the cause for this deviation. 


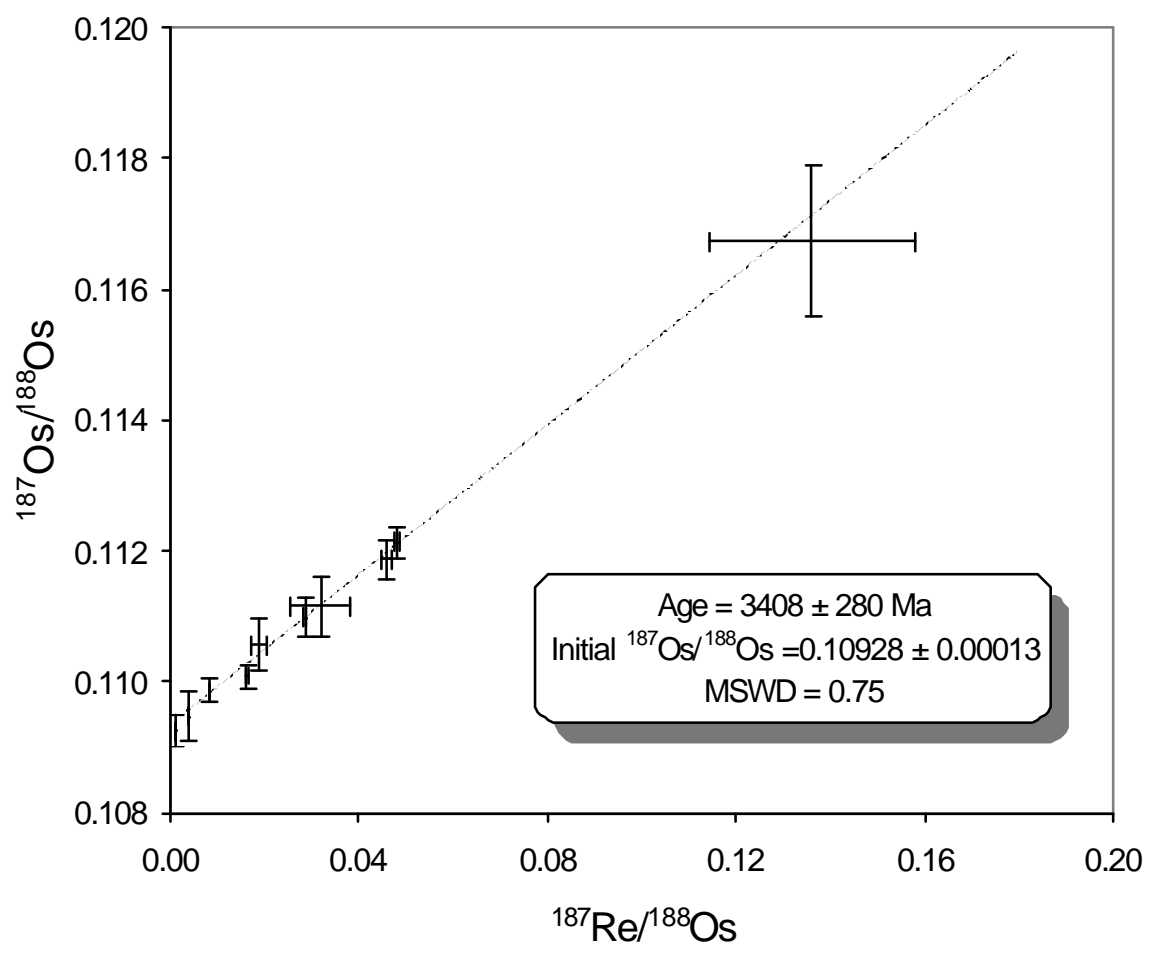

Figure 3: Re-Os isochron diagram with regression data for 10 of the 11 group I sulfides.

\section{DISCUSSION AND CONCLUSIONS}

Panda diamonds with silicate inclusions (Stachel and Harris, in press) have been proposed to originate from the deeper, moderately melt-depleted parts of the central Slave lithosphere (Griffin et al., 1999). The nitrogen in the diamonds carrying the group I and group II sulfides studied here is significantly less aggregated than the nitrogen in the bulk of the silicate-bearing diamonds (Westerlund et al., this volume). This is indicative of a comparatively shallow level of origin in the diamondiferous mantle. Assuming that the sulfides hosted the bulk of the $\mathrm{Re}$ and Os in their formation environment, their extremely low Re/Os ratios imply formation in a severely melt-depleted environment. Together with the nitrogen aggregation characteristics of the diamonds, this suggests that the diamonds originate from the shallow lithosphere, which displays mineral chemical compositions indicative of a significantly higher degree of melt-depletion compared to the deeper Slave lithosphere (Griffin et al., 1999). This calls into question the idea that the deeper mantle is typically more melt-depleted.

The Re-Os isotope characteristics of the sulfides are indicative of a mid-Archean age with a preferred age of
$3408 \pm 280 \mathrm{Ma}$. The age is similar to crustal ages in the western parts of the Slave craton while it is significantly older than crustal ages found in the Contwoyto terrain to the east of the $\mathrm{Nd}$ isotope boundary (Davis and Hegner, 1992) where the Panda kimberlite occurs. It is proposed that the analyzed samples represent a lithospheric component, which was emplaced tectonically during a collision between a western Slave meso-Archean proto-craton and an eastern Slave arc-terrain. In situ subduction of oceanic lithosphere as a mechanism of forming the sub-cratonic lithosphere represented by the current samples is not viable since the obtained age predates a proposed collision around 2.7 Ga (Kusky, 1989; Bleeker et al., 1999). Further, since the age also represents the age of the diamonds, the emplaced lithosphere must have reached depths of at least $\sim 150 \mathrm{~km}$.

The initial ${ }^{187}$ Os $/{ }^{188}$ Os $(0.1093)$ ratio is slightly elevated compared to the primitive upper mantle at $3.4 \mathrm{Ga}$ (0.1040). This extends the previous record of ancient suprachondritic mantle sources (deduced from mantle melts) from $2.8 \mathrm{Ga}$ (Puchtel et al., 2001) to $3.4 \mathrm{Ga}$. The initial ${ }^{187} \mathrm{Os} /{ }^{188} \mathrm{Os}$ demands a source, which had a suprachondritic Re/Os ratio for some time prior to the diamond/sulfide formation. This is the opposite to what is seen in mid-ocean ridge melting residues and 
suggests that the mantle source for the sulfides was enriched. Whether this was due to a potentially suprachondritic lower mantle (Walker et al., 1997), radiogenic Os from the outer core (Walker et al, 1995), or mantle enrichment due to an early form of Hadean crustal recycling is not known.

As for harzburgitic diamonds from the Kaapvaal and Siberian cratons (Richardson et al., 1984; Pearson et al., 1999a), the obtained age is meso-Archaean which may indicate that the process responsible for the formation of peridotitic diamonds preferentially occurred during this time of the Earth's history.

\section{REFERENCES}

Bleeker, W., Ketchum, J.W.F., Davis, W.J., 1999. The Central Slave Basement Complex, Part II: age and tectonic significance of high-strain zones along the basement-cover contact. Can. J. Earth Sci., 36, 1111-1130.

Carlson, R.W., Pearson, D.G., Boyd, F.R., Shirey, S.B., Irvine, G., Menzies, A.H., Gurney, J.J., 1999.

Re-Os systematics of lithospheric peridotites: implications for lithoshpere formation and preservation. Proc. 7 Int. Kimb. Conf. Cape Town, South Africa, Vol. 1, pp. 99-108.

Craig, J.R., Kullerud, G., 1969. Phase relations in the $\mathrm{Cu}-\mathrm{Fe}-\mathrm{Ni}-\mathrm{S}$ system and their application to magmatic ore deposits. Econ. Geol. Monograph, 4, 344-358.

Davis, W.J., Hegner, E., 1992. Neodymium isotopic evidence for the tectonic assembly of late Archean crust in the Slave province, northwest Canada. Contr. Min Petrol., 111, 493-504.

Griffin, W.L., Doyle, B.J., Ryan, C.G., Pearson, N.J., O'Reilly, S.Y., Davies, R., Kivi, K., Van Achterberg, E., Natapov, L., 1999. Layered mantle lin the Lac de Gras area, Slave craton: Composition, structure and origin. J. Petrol., 40, 705-727.

Kusky, T.M., 1989. Accretion of the Archean Slave province. Geology, 17, 63-67.

Pearson, D.G., Shirey, S.B., Harris, J.W., Carlson, R.W., 1998. Sulphide inclusions in diamonds from the Koffiefontein kimberlite, S Africa: constraints on diamond ages and mantle Re-Os systematics. EPSL, $160,311-326$.

Pearson, D.G., Shirey, S.B., Bulanova, G.P., Carlson, R.W., Milledge, H.J., 1999a. Dating and paragenetic distinction of diamonds using the Re-Os isotope system: application to some Siberian diamonds. Proc. 7 Int. Kimb. Conf. Cape Town, South Africa, Vol. 1, pp. 637-643.

Pearson, D.G., Davies, R.M., Shirey, S.B., Carlson, R.W., Griffin, W.L., 1999b. The age and origin of eastern Australian diamonds: Re-Os isotope evidence from sulfide inclusions in two diamonds from Wellington, New South Wales. 7 Int. Kimb. Conf. Cape Town, South Africa, Extended Abstracts, pp. 664-666.

Puchtel, I.S., Brugmann, G.E., Hofmann, A.W., 2001. 187Osenriched domain in an Archaean mantle plume: evidence from $2.8 \mathrm{Ga}$ komatiites of the Kostomuksha greenstone belt, NW Baltic Shield. EPSL, 186, 513526.

Richardson, S.H., Gurney, J.J., Erlank, A.J., Harris, J.W., 1984. Origin of diamonds in old enriched mantle. Nature, 310, 198-202.

Richardson, S.H., Shirey, S.B., Harris, J.W., Carlson, R.W., 2001. Archaean subduction recorded by Re-Os isotopes in eclogitic sulfide inclusions in Kimberley diamonds. EPSL, 191, 257-266.

Shirey, S.B., Carlson, R.W., Richardson, S.H., Menzies, A.H., Gurney, J.J., Pearson, D.G., Harris, J.W., Wiechert, U., 2001. Geophys. Res. Lett., 28(13), 2509-2512.

Shirey, S.B., Harris, J.W., Richardson, S.H., Fouch, M.J., James, D.E., Cartigny, P., Deines, P., Viljoen, F., 2002. Science, 297, 1683-1686.

Stachel, T., Harris, J.W., in press. Peridotitic inclusions in diamonds from the Slave and the Kaapvaal cratons similarities and differences based on a preliminary data set. Lithos.

Walker, R.J., Morgan, J.W., Horan, M., 1995. ${ }^{187}$ Os enrichment in some mantle plume sources: Evidence for core-mantle interaction? Science, 269, 819-822.

Walker, R.J., Morgan, J.W., Hanski, E.J., Smolkin, V.F., 1997. Re-Os systematics of early Proterozoic ferropicrites, Pechenga complex, northwestern Russia: Evidence for ancient ${ }^{187}$ Os-enriched plumes. Geochim. Cosmochim. Acta, 61(15), 3145-3160.

Westerlund, K.J., Hauri, E.H., Gurney, J.J., (8IKC, this volume). FTIR absorption and nitrogen and carbonn isotope microanalysis of mid-Archaean diamonds from the Panda kimberlite, Slave craton.

Contact: KJ Westerlund, Private Bag, Rondebosch, 7700,

South Africa, E-mail: Kalle@geology.uct.ac.za 